\title{
Novel NiMgOH-rGO-Based Nanostructured Hybrids for Electrochemical Energy Storage Supercapacitor Applications: Effect of Reducing Agents
}

\author{
Konda Shireesha ${ }^{1}$, Thida Rakesh Kumar ${ }^{1}$, Tumarada Rajani ${ }^{2}$, Chidurala Shilpa Chakra ${ }^{1, *(1) \text {, }}$ \\ Murikinati Mamatha Kumari ${ }^{3} \mathbb{D}$, Velpula Divya ${ }^{1}$ and Kakarla Raghava Reddy ${ }^{4} *$ (D) \\ 1 Center for Nano Science and Technology, Institute of Science and Technology, JNTU Hyderabad, \\ Hyderabad 500090, India; shireeshakonda483@gmail.com (K.S.); rakhichinna4a8@gmail.com (T.R.K.); \\ divya.velpula905@gmail.com (V.D.) \\ 2 Department of Humanities and Sciences, VNR VJIET, Hyderabad 500090, India; \\ rajaniindrakanti691@gmail.com \\ 3 Department of Materials Science and Nanotechnology, Yogi Vemana University, Kadapa 516005, India; \\ mamatha@yogivemanauniversity.ac.in \\ 4 School of Chemical and Biomolecular Engineering, The University of Sydney, Sydney, NSW 2006, Australia \\ * Correspondence: shilpachakra.nano@jntuh.ac.in (C.S.C.); reddy.chem@gmail.com or \\ raghava.kakarla@sydney.edu.au (K.R.R)
}

\section{check for}

updates

Citation: Shireesha, K.; Kumar, T.R.; Rajani, T.; Chakra, C.S.; Kumari, M.M.; Divya, V.; Raghava Reddy, K. Novel NiMgOH-rGO-Based

Nanostructured Hybrids for Electrochemical Energy Storage Supercapacitor Applications: Effect of Reducing Agents. Crystals 2021, 11, 1144. https://doi.org/ $10.3390 /$ cryst 11091144

Academic Editor: Leonid Kustov

Received: 30 July 2021

Accepted: 16 September 2021

Published: 19 September 2021

Publisher's Note: MDPI stays neutral with regard to jurisdictional claims in published maps and institutional affiliations.

Copyright: (c) 2021 by the authors. Licensee MDPI, Basel, Switzerland. This article is an open access article distributed under the terms and conditions of the Creative Commons Attribution (CC BY) license (https:// creativecommons.org/licenses/by/ $4.0 /)$.
Abstract: This paper describes the synthesis and characterization of NiMgOH-rGO nanocomposites made using a chemical co-precipitation technique with various reducing agents (e.g., $\mathrm{NaOH}$ and $\mathrm{NH}_{4} \mathrm{OH}$ ) and reduced graphene oxide at $0.5,1$, and 1.5 percent by weight. UV-visible spectroscopy, Fourier-transform infrared spectroscopy, X-ray diffraction, a particle size analyzer, and cyclic voltammetry were used to characterize the composite materials. The formation of the NiMgOH-rGO nanocomposite with crystallite sizes in the range of 10-40 nm was inferred by X-ray diffraction patterns of materials, which suggested interlayers of $\mathrm{Ni}(\mathrm{OH})_{2}$ and $\mathrm{Mg}(\mathrm{OH})_{2}$. The interactions between the molecules were detected using Fourier-transform infrared spectroscopy, while optical properties were studied using UV-visible spectroscopy. A uniform average particle size distribution in the range of 1-100 $\mathrm{nm}$ was confirmed by the particle size analyzer. Using cyclic voltammetry and galvanostatic charge/discharge measurements in a $6 \mathrm{M} \mathrm{KOH}$ solution, the electrochemical execution of NiMgOH-rGO nanocomposites was investigated. At a $1 \mathrm{~A} / \mathrm{g}$ current density, the NiMgOH-rGO nanocomposites prepared with $\mathrm{NH}_{4} \mathrm{OH}$ as a reducing agent had a higher specific capacitance of 1977 F/g. The electrochemical studies confirmed that combining rGO with $\mathrm{NiMgOH}$ increased conductivity.

Keywords: NiMgOH; carbon nanomaterials; nanostructured hybrid electrodes; electrochemical properties; specific capacitance; energy storage supercapacitors

\section{Introduction}

Supercapacitors are more flexible to a demanding work environment because of their superior performance in charge-discharge cycles, high power density, and high storage [1,2]. Supercapacitors, also known as ultra-capacitors, are alternative energy storage devices that help to reduce the use of fossil fuels and other environmental issues such as air pollution [3]. Many energy sources, such as solar, wind power, and geothermal heat, have been investigated in recent years to see if they can reduce air pollution and solve environmental problems. However, access to these resources is not always possible. As a result, developing relevant energy storage devices with large storage capacities for storing these energies is critical. Supercapacitors have been used to store electrical energy in backup power systems, portable electronics, telecommunications, and vehicles, among other applications [4-6]. Practically, energy storage systems are widely demonstrated and 
reported for good performance and robustness [7,8]. The physicochemical properties of the electrode material are important in improving the supercapacitor's performance $[9,10]$.

Pseudocapacitive metal oxides/hydroxides (e.g., $\mathrm{NiO}, \mathrm{MgO}, \mathrm{Mg}(\mathrm{OH})_{2}, \mathrm{Ni}(\mathrm{OH})_{2}$, $\mathrm{MnO}_{2}, \mathrm{Co}(\mathrm{OH})_{2}$, and $\left.\mathrm{NiCo}_{2} \mathrm{O}_{4}\right)$ have been used for decades on account of their higher energy density and specific capacitance [11-15]. Binary systems of metal hydroxides are attractive because of their enhanced electrochemical properties. At the same time, little research has self-addressed the synthesis of binary metal hydroxides [16]. To develop a highperformance supercapacitor, $\mathrm{Mg}$ powder was sacrificed with nickel salt aqueous precursor solutions (NiAl hydroxide [17], NiCo binary hydroxide [18,19], and NiMn hydroxide [20]) with improved pseudocapacitive behavior. Magnesium hydroxide $\left(\mathrm{Mg}(\mathrm{OH})_{2}\right)$ and nickel hydroxide $\left(\mathrm{Ni}(\mathrm{OH})_{2}\right)$ are two of the most extensively used pseudocapacitive materials. $\mathrm{Mg}(\mathrm{OH})_{2}$ is an alkaline metal hydroxide with a variety of advantages, including low equivalent weight, low cost, low toxicity, and environmental friendliness [21], which results in a good option for electrochemical energy storage. Nickel hydroxide is a versatile functional substance with a wide range of uses on account of its higher electrochemical capacity. These characteristics benefit a variety of devices in the fields of transportation, electronics, agriculture, biomedicine, automotive, and aerospace applications [22-25].

Carbon derivatives are also employed as electrode materials to increase the dispersion and electron transport of binary metal hydroxides and their stability and electrolyte contact area. Among carbon derivatives, $\mathrm{rGO}$ is an efficient electrode material for supercapacitor applications due to its ultra-high surface area and outstanding conductivity, as well as excellent mechanical and chemical stability, low cost, and large-scale production [15]. Graphene-based supercapacitors have been broadly studied due to their excellent properties such as large surface area, high porosity, and good electrical properties [26]. The addition of rGO will enhance the performance of the supercapacitor [27]. However, the properties of the electrode material and the interaction between the electrode and electrolyte will determine the supercapacitor's performance. Reducing agents are essential in controlling the size and morphology of nanostructures, which impact their potential in a variety of fields, including supercapacitors. According to published reports, the reducing agents used during synthesis, such as citric acid (CA), ammonium hydroxide $\left(\mathrm{NH}_{4} \mathrm{OH}\right)$, potassium iodide (KI), hydrazine hydrate $(\mathrm{HH})$, ethylene glycol (EG), $\mathrm{NaBH}_{4}(\mathrm{NBH})$, and formic acid (FA) [28], produced different structures and surface areas that had a greater impact on specific capacitance. The reducing agent used has a significant impact on the effective surface area and agglomeration of nanocomposites, which results in improved capacitive performance. Compared to different reducing agents, $\mathrm{NaOH}$ and $\mathrm{NH}_{4} \mathrm{OH}$ show the best results in crystallinity and purity [29].

Herein, a facile co-precipitation method was reported to synthesize novel nanostructured hybrids consisting of double metal-hydroxide and rGO for electrochemical energy storage supercapacitor applications. The capacitance behavior of the NiMgOH-rGO nanocomposite was studied systematically with the effect of reducing agents $\left(\mathrm{NaOH} / \mathrm{NH}_{4} \mathrm{OH}\right)$. The addition of rGO during the synthesis of $\mathrm{NiMgOH}-\mathrm{rGO}$ promotes high surface area, which leads to the good dispersion of $\mathrm{NiMgOH}$ particles over the rGO matrix. This higher surface area of the material promotes high diffusion of the $\mathrm{e}^{-}$, which can enhance the value of specific capacitance of the composites. This methodology provides a controlled, modified particle size and composition by which homogeneity can be maintained. To investigate the physicochemical and electrochemical energy storage properties of materials, $\mathrm{X}$-ray diffraction (XRD), an ultraviolet-visible spectrophotometer (UV-Visible), Fourier-transform infrared spectroscopy (FTIR), a particle size analyzer (PSA), and electrochemical property measurements such as cyclic voltammetry (CV) curves, galvanostatic charge-discharge (GCD) cycles, and electrochemical impedance spectroscopy (EIS) were used.

\section{Materials and Methods}

Reagents used in this investigation, including nickel nitrate $\left(\mathrm{Ni}\left(\mathrm{NO}_{3}\right)_{2} \cdot 6 \mathrm{H}_{2} \mathrm{O}\right)$, magnesium nitrate $\left(\mathrm{Mg}\left(\mathrm{NO}_{3}\right)_{2} \cdot 6 \mathrm{H}_{2} \mathrm{O}\right), \mathrm{NaOH}$, and $\mathrm{NH}_{4} \mathrm{OH}$, were procured from FINAR $(99.99 \%$ 
pure, Finar Limited, Gujarat, India), while reduced graphene oxide was acquired from Platonic India Pvt. Ltd. (research grade).

2.1. Synthesis of $\mathrm{NiMgOH}$ and $\mathrm{NiMgOH}-\mathrm{rGO}$ Using Co-Precipitation Method with $\mathrm{NaOH}$ and $\mathrm{NH}_{4} \mathrm{OHas}$ Reducing Agents

In this work, the co-precipitation method was adopted for synthesizing $\mathrm{NiMgOH}$ and $\mathrm{NiMgOH}-\mathrm{rGO}$ nanocomposites. $0.1 \mathrm{M}$ of nickel nitrate and magnesium nitrate were dissolved in $200 \mathrm{~mL}$ of distilled water. Different weight percentages $(0,0.5 \%, 1 \%$, and $1.5 \%)$ of rGO were added to each of the $0.1 \mathrm{M}$ of nickel nitrate and magnesium nitrate solutions and stirred for $2 \mathrm{~h}$ at $80^{\circ} \mathrm{C}$. A reducing agent of $2 \mathrm{M}$ of $\mathrm{NaOH}$ was added dropwise to the above mixture until the $\mathrm{pH}$ reached 7 . After precipitation formation, the product (NiMgOH-rGO) was filtered and dried in a hot air oven at $90^{\circ} \mathrm{C}$ for $12 \mathrm{~h}$.

Various weight percentages $(0,0.5 \%, 1 \%$, and $1.5 \%)$ of $(\mathrm{NiMgOH}-\mathrm{rGO})$ were also prepared similarly with $\mathrm{NH}_{4} \mathrm{OH}$ as a reducing agent. All the nanocomposites synthesized by these two reducing agents were labeled appropriately, as shown in Table 1.

Table 1. Synthesis of NiMgOH and NiMgOH-rGO $(0.5 \%, 1 \%$, and $1.5 \%)$ nanocomposites by chemical co-precipitation technique.

\begin{tabular}{ccc}
\hline \multirow{2}{*}{ Samples Prepared } & \multicolumn{2}{c}{ Reducing Agents } \\
\cline { 2 - 3 } & $\mathrm{NaOH}$ & $\mathrm{NH}_{4} \mathrm{OH}$ \\
\hline $\mathrm{NiMgOH}$ & $\mathrm{NMN}$ & $\mathrm{NMNH}$ \\
\hline $\mathrm{NiMgOH}-0.5 \% \mathrm{rGO}$ & $\mathrm{NMN}-1$ & $\mathrm{NMNH}-1$ \\
\hline $\mathrm{NiMgOH}-1 \% \mathrm{rGO}$ & $\mathrm{NMN}-2$ & $\mathrm{NMNH}-2$ \\
\hline $\mathrm{NiMgOH}-1.5 \% \mathrm{rGO}$ & $\mathrm{NMN}-3$ & $\mathrm{NMNH}-3$ \\
\hline
\end{tabular}

\subsection{Characterization}

The XRD technique was carried out by a Bruker D8 (Bruker Corporation, Billerica, MA, USA) to find out the crystal structure, phase, and average crystallite size of the synthesized samples. In addition, the Systronics, double beam UV-Vis spectrophotometer 2202 (Systronics, Gujarat, India) and Bruker Alpha II FTIR spectrometer (Bruker Corporation, Billerica, MA, USA) were used to study the optical absorption and nature of bonding, respectively, in the supercapacitor. The Horiba SZ-100 Particle Size Analyzer (HORIBA, Ltd., Kyoto, Japan) was used to determine the average particle size. CH6112E was used for electrochemical analysis of the NiMgOH-rGO nanocomposites.

\section{Results and Discussions}

\subsection{X-ray Diffraction (XRD) Studies}

$\mathrm{XRD}$ analysis was used to characterize the structural properties of several $\mathrm{NiMgOH}$ nanocomposites. Figure $1 \mathrm{a}-\mathrm{c}$ depict the $\mathrm{XRD}$ pattern of $\mathrm{NiMgOH}$ with various percentages of rGO and pure rGO. The formation of the peaks suggests that $\mathrm{Ni}(\mathrm{OH})_{2}$ and $\mathrm{Mg}(\mathrm{OH})_{2}$ are effective and stable consolidations in the composite structure. The obtained XRD patterns (Figure 1a,b) are in a cooperative agreement with the reported JCPDS 44-1482 of $\mathrm{Mg}(\mathrm{OH})_{2}$ [22] and JCPDS 38-0715 of $\beta-\mathrm{Ni}(\mathrm{OH})_{2}$ [17]. The diffraction peaks at $17.2^{\circ}$, $33.0^{\circ}, 38.5^{\circ}$, and $52.1^{\circ}$ indicate $\left(\begin{array}{lll}0 & 0 & 1\end{array}\right),\left(\begin{array}{lll}1 & 0 & 0\end{array}\right),\left(\begin{array}{lll}1 & 0 & 1\end{array}\right)$, and $\left(\begin{array}{lll}1 & 1 & 0\end{array}\right)$ planes of $\beta-\mathrm{Ni}(\mathrm{OH})_{2}$, while the diffraction peaks at $18.48^{\circ}, 32.80^{\circ}, 58.64^{\circ}, 62.02^{\circ}, 68.16^{\circ}$, and $72^{\circ}$ represent $(001)$, (1 $\left.\begin{array}{lll}0 & 0\end{array}\right),\left(\begin{array}{lll}1 & 1 & 0\end{array}\right),\left(\begin{array}{lll}1 & 1 & 1\end{array}\right),\left(\begin{array}{lll}1 & 0 & 3\end{array}\right)$, and (2 0101$)$ crystal planes of hexagonal brucite $\mathrm{Mg}(\mathrm{OH})_{2}$ [22]. The diffraction peaks in Figure $1 \mathrm{a}-\mathrm{c}$ at $25.19^{\circ}$ indicate the (002) plane of rGO [30]. The formation of a peak around $25.9^{\circ}$ shows the semi-crystalline nature of the composite and confirms the interaction of the rGO with $\mathrm{NiMgOH}$ [31], indicating the interfacial phenomena occurrence [32]. 

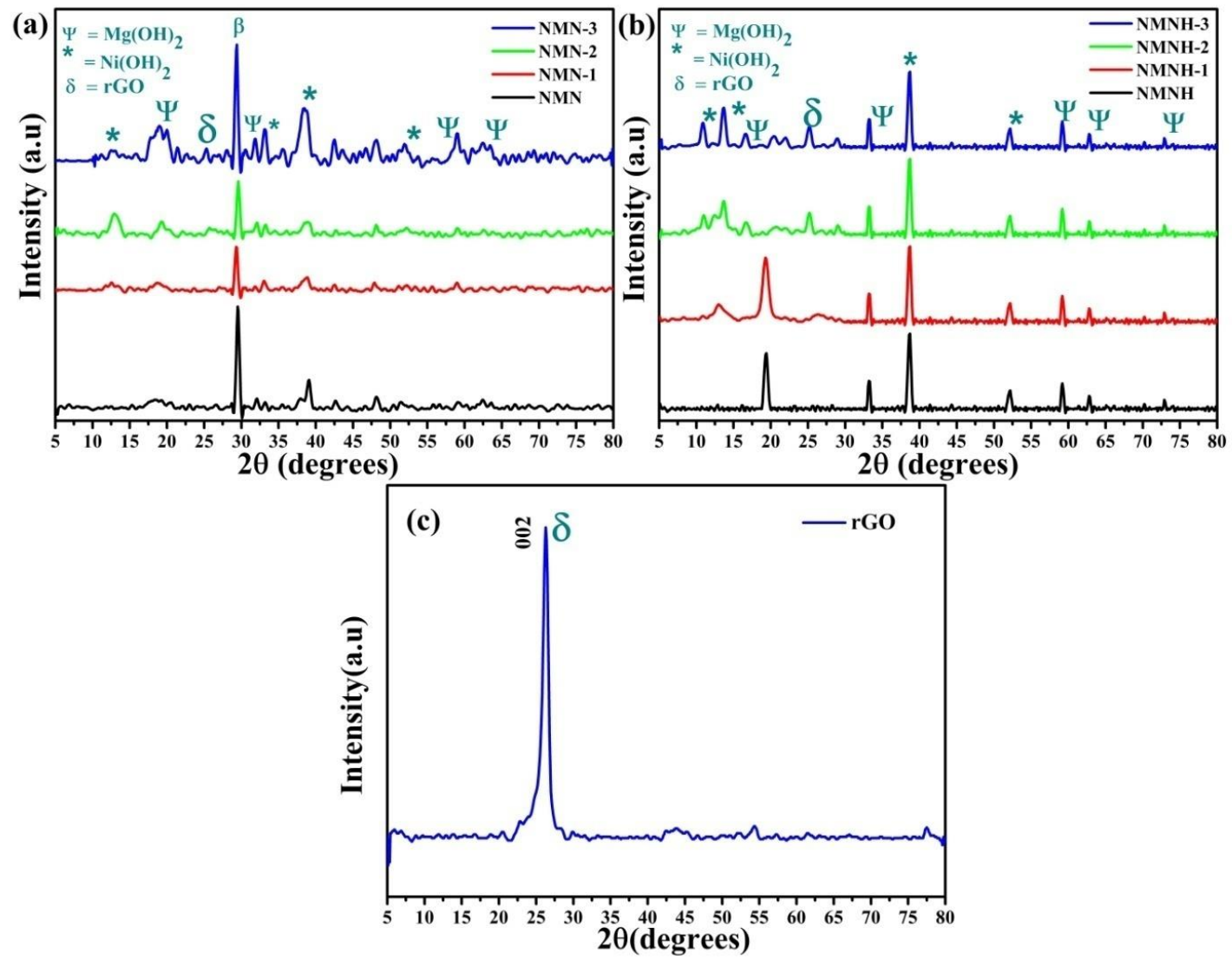

Figure 1. XRD patterns of (a) NMN, NMN-1, NMN-2, and NMN-3; (b) NMNH, NMNH-1, NMNH-2, and NMNH-3; and (c) rGO.

From Figure 1a,b, as the concentration of rGO increased from $0.5 \%$ to $1.5 \%$ by weight, there was an increase in the intensity of the diffraction peaks at a $2 \theta$ value of $25.9^{\circ}$. Interesting facts were also observed, such as the broadening of peak intensities in the case of NiMgOH-rGO (Figure 1a), and this may be due to the presence of hydrogen bonding between $\mathrm{NiMgOH}$ and $\mathrm{rGO}$, as well as due to the decrease in particle size [33].

The peak intensities of NiMgOH-rGO were similar to $\mathrm{NiMgOH}$ in some cases and were due to the increased thermal movement of rGO hindering the movement of $\mathrm{NiMgOH}$, which restricts their closest approach. It is of interest to note that the enhanced peak intensities with the increased concentration of rGO may be due to the formation of a network favored by the conditions for the formation of crystallites [34]. The shifts in $2 \theta$ values in some cases were due to cationic redistribution, enhanced crystallization, or an associated reason due to reorganization of the atoms in the crystal lattice that occurs with the interaction of rGO with $\mathrm{NiMgOH}$ [35]. This process introduced a distortion that affected the structure and the distance between the neighboring ions [36]. The average crystallite sizes of the obtained composites were determined from Debye-Scherer's formula.

$$
D=K \lambda / \beta \cos \theta
$$

where $D$ denotes the crystallite size in nanometers, $K$ denotes the constant, $\lambda$ is the wavelength of $\mathrm{Cu}$ radiation $(0.15406 \mathrm{~nm}), \beta$ is the full-width at half-maximum of individual peaks, and $\theta$ is the Bragg angle in radians. The crystallite size distribution of various $\mathrm{NiMgOH}$ composites is shown in Table 2. 
Table 2. Average particle size and crystallite size from XRD of NMN, NMN-1, NMN-2, NMN-3, NMNH, NMNH-1, NMNH-2, and NMNH-3.

\begin{tabular}{cccc}
\hline S.No & Name of Sample & $\begin{array}{c}\text { Average Particle Size } \\
\text { from PSA (nm) }\end{array}$ & $\begin{array}{c}\text { Average Crystallite Size } \\
\text { from XRD (nm) }\end{array}$ \\
\hline 1 & NMN & 47 & 35 \\
2 & NMN-1 & 34 & 19 \\
3 & NMN-2 & 21 & 16 \\
4 & NMN-3 & 16 & 13 \\
5 & NMNH & 33 & 23 \\
6 & NMNH-1 & 29 & 19 \\
7 & NMNH-2 & 26 & 16 \\
8 & NMNH-3 & 22 & 15 \\
\hline
\end{tabular}

\subsection{Particle Size Analysis (PSA)}

The PSA technique was performed on the synthesized materials to understand the distribution and average particle size and is based on the principle of Brownian motion of individual particles. The smaller particles have more significant Brownian motion, and they move more rapidly with the solvent molecules. Laser diffraction is used to determine the angular variation in the intensity of light scattered as a laser beam passes through a dispersed particulate sample. The particle size is expressed in terms of volume-equivalent spherical diameter. The histograms indicated good uniformity of the material (Figure 2a,b). Nanocomposites are smaller than $100 \mathrm{~nm}$ in dimension, and it was found that the particle size decreased with the percentage of $\mathrm{rGO}$, which is supported by existing XRD data [37]. The size of a crystallite is smaller than the size of a particle, and within a particle, there are many crystals with the same orientation [38]. The average particle size $(\mathrm{nm})$ of all materials is provided in Table 2.

\subsection{Fourier-Transform Infrared Spectroscopic Studies}

Infrared radiation absorption causes the vibrations of atoms in a molecule or crystal lattice to be excited, resulting in bands in the spectra that are generally expressed in terms of the unit wave number in $\mathrm{cm}^{-1}$. After mixing the FTIR spectra with an IR transparent material, $\mathrm{KBr}$, they are compressed into a clear pellet for analysis. The most effective technique for deciphering the bonding of synthesized nanocomposite materials is FTIR spectroscopy. The FTIR spectra obtained for $\mathrm{NiMgOH}$ nanocomposites with and without rGO are shown in Figure 3a,b.

The sharp vibration bands at $3750 \mathrm{~cm}^{-1}$ for NiMgOH-rGO and $3670 \mathrm{~cm}^{-1}$ for NiM$\mathrm{gOH}$ indicate the stretching vibration of free hydroxyl groups on the inner surface of the multi-layered $\beta-\mathrm{Ni}(\mathrm{OH})_{2}$ structures. This sharp band occurred due to the nonallowance of a water molecule into the short inner layer space of $\beta-\mathrm{Ni}(\mathrm{OH})_{2}$ to form a hydrogen bond, while the broadband at $\sim 3451 \mathrm{~cm}^{-1}$ is attributed to the stretching mode of hydrogenbonded O-H groups within the layered structure [39]. The band at $541 \mathrm{~cm}^{-1}$ indicates bending or in-plane deformation vibration of the hydroxyl groups and $\mathrm{Ni}-\mathrm{O}$ stretching vibrations that suggest that $\mathrm{Ni}(\mathrm{OH})_{2}$ is in the $\beta$-phase [40]. The sharp peak at $3850 \mathrm{~cm}^{-1}$ is associated with the stretching vibration, while that at $1450 \mathrm{~cm}^{-1}$ reflects bending vibrations of the $\mathrm{O}-\mathrm{H}$ group in $\mathrm{Mg}(\mathrm{OH})_{2}$ [41].

In addition, $\mathrm{rGO}$ was also presented in $\mathrm{NiMgOH}$ with different percentages and associated with various bands, reflecting the presence of $\mathrm{O}-\mathrm{H}$ groups $\left(3400 \mathrm{~cm}^{-1}\right), \mathrm{C}-\mathrm{H}$ stretching $\left(2957 \mathrm{~cm}^{-1}\right), \mathrm{C}-\mathrm{H}$ bending $\left(2092 \mathrm{~cm}^{-1}\right.$ and $\left.1653 \mathrm{~cm}^{-1}\right), \mathrm{C}=\mathrm{C}$ groups $\left(1653 \mathrm{~cm}^{-1}\right)$, O-H deformation $\left(1375 \mathrm{~cm}^{-1}\right)$, C-OH deformation $\left(1393 \mathrm{~cm}^{-1}\right)$, C-O groups $\left(1117 \mathrm{~cm}^{-1}\right)$, and vibration of absorbing water molecules $\left(1653 \mathrm{~cm}^{-1}\right)$ [42]. The broadening of $\mathrm{O}-\mathrm{H}$ bands with the increased percentage of rGO reflects intra-molecular hydrogen bonding between $\mathrm{NiMgOH}$ and the corresponding rGO. 
(a)
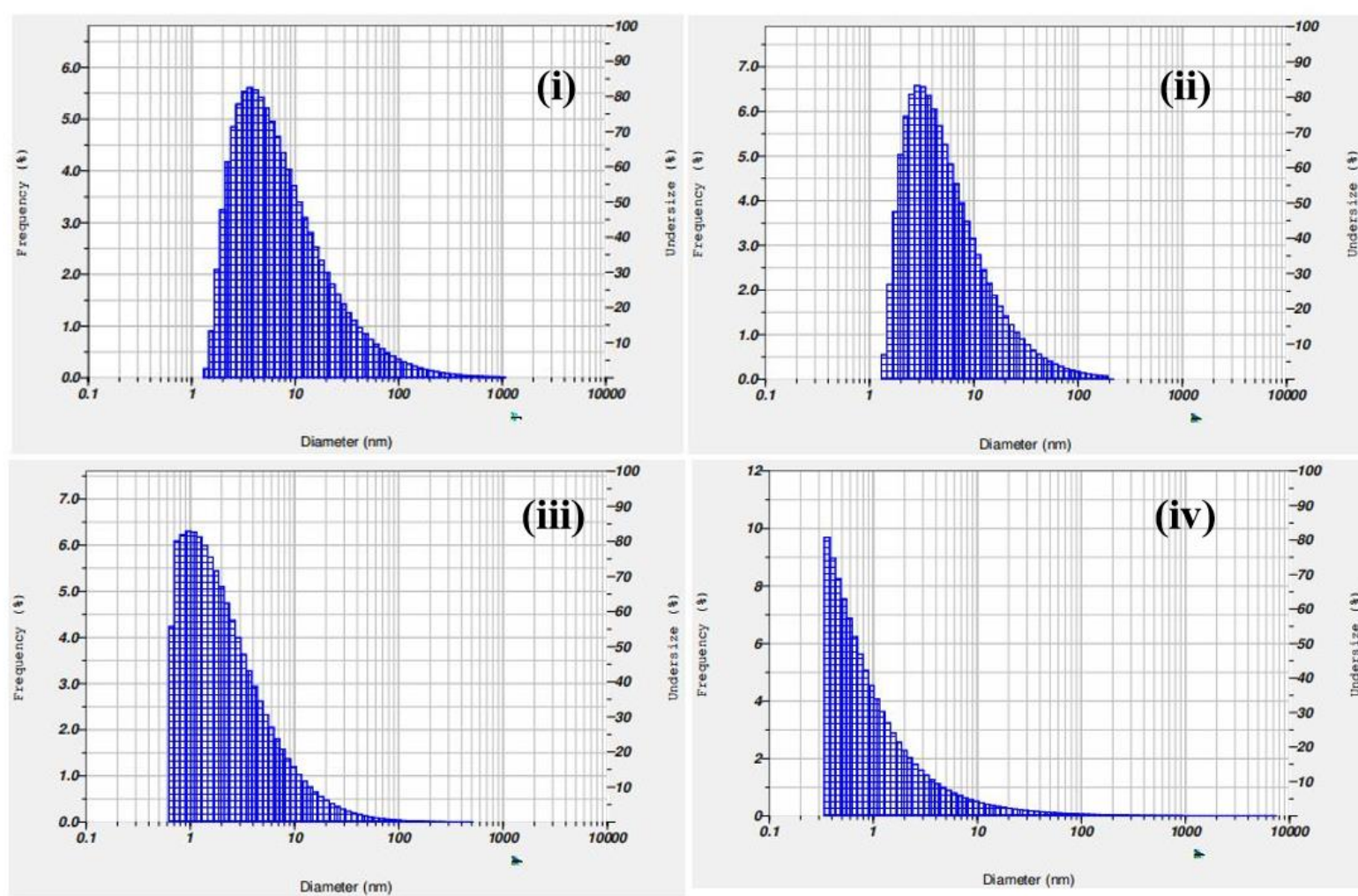

(b)
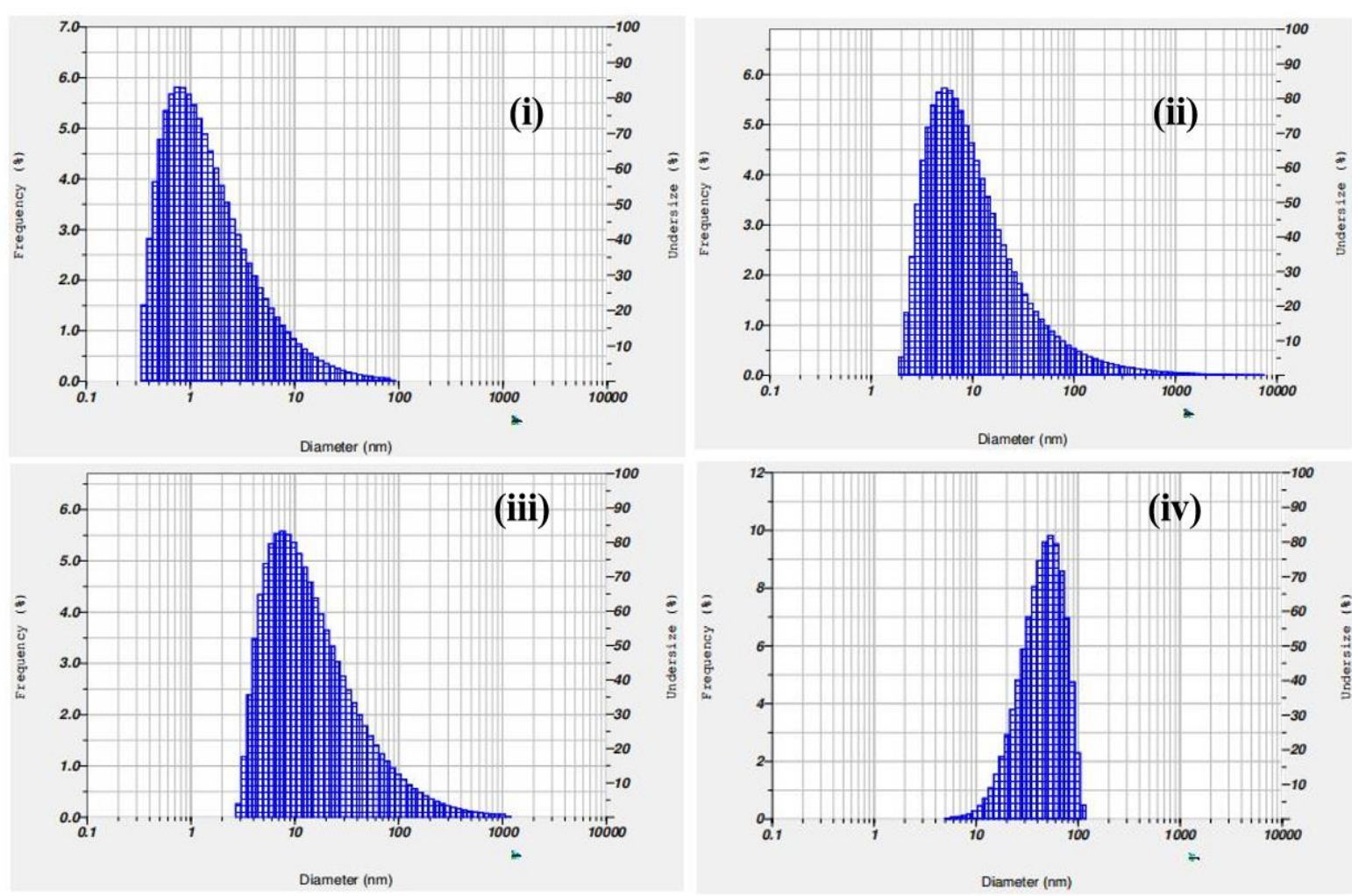

Figure 2. Particle size analysis of (a) (i) NMN (ii) NMN-1 (iii) NMN-2 (iv) NMN-3; and (b) (i) NMNH (ii) NMNH-1 (iii) NMNH-2 and (iv) NMNH-3. 

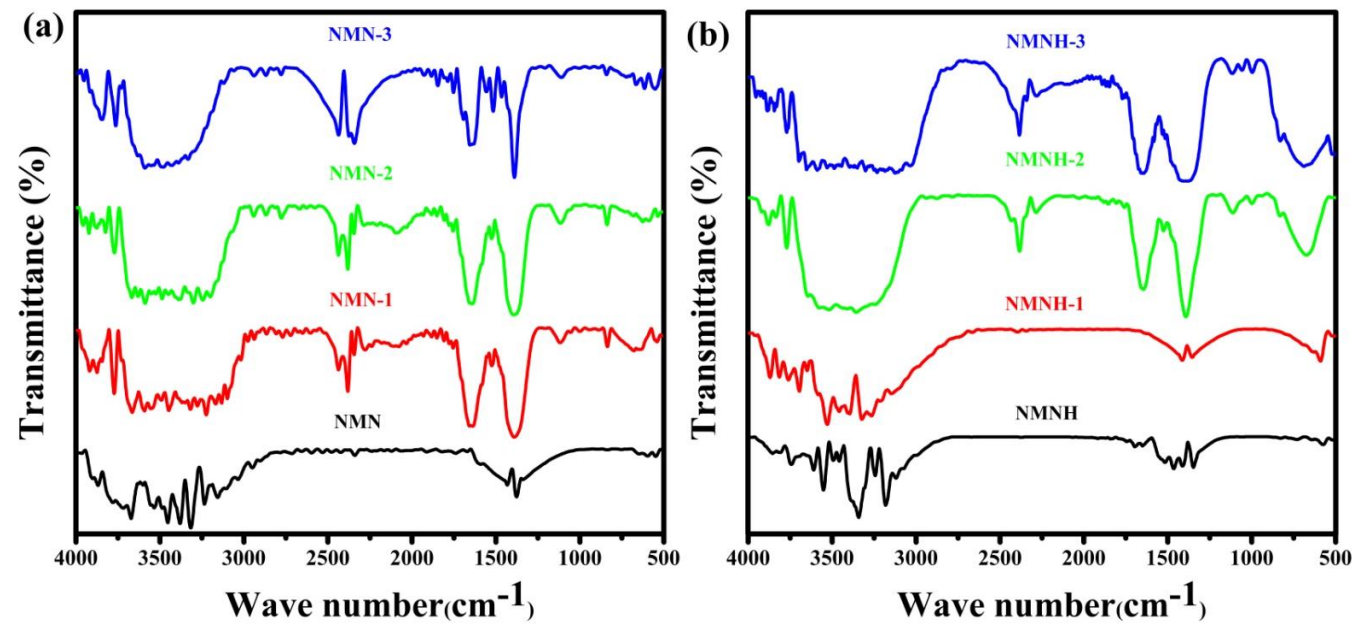

Figure 3. FTIR spectra of (a) NMN, NMN-1, NMN-2, and NMN-3; and (b) NMNH, NMNH-1, $\mathrm{NMNH}-2$, and NMNH-3.

\subsection{UV-Visible Spectroscopy}

For UV-visible spectroscopic studies, the sample preparation was performed by dissolving the synthesized powders in deionized water as a solvent and sonicating them for $15 \mathrm{~min}$. After the complete dispersion of powder, the solution was transferred into a transparent quartz cuvette for UV analysis. The optical absorbance spectra were recorded in the range of $200-500 \mathrm{~nm}$. The recorded spectra are shown in Figure $4 a, b$. The peak of $\mathrm{Mg}(\mathrm{OH})_{2}$ at $234 \mathrm{~nm}$ showed blueshifts at $230 \mathrm{~nm}, 232 \mathrm{~nm}$, and $233 \mathrm{~nm}$ for NMN-1, NMN-2, and $\mathrm{NMN}-3$, respectively, while the peak of $\mathrm{Mg}(\mathrm{OH})_{2}$ at $230 \mathrm{~nm}$ showed redshifts of $234 \mathrm{~nm}$, $235 \mathrm{~nm}$, and $238 \mathrm{~nm}$ for NMNH-1, NMNH-2, and NMNH-3, respectively, indicating the effect of reducing agents. The absorption peak around $232 \mathrm{~nm}$ corresponds to $\mathrm{rGO}$, and the presence of $\pi-\pi^{*}$ transitions of aromatic $\mathrm{C}-\mathrm{C}$ bonds and $\mathrm{n}-\pi^{*}$ transitions of $\mathrm{C}=\mathrm{O}$ results in a broad shoulder peak around $270-300 \mathrm{~nm}$. Due to the restoration of $\pi$ electronic conjugation within the reduced graphene oxide, the $\mathrm{Mg}(\mathrm{OH})_{2}$-rGO nanocomposites exhibited strong and broad absorption in the visible region [43]. The clear peaks at $350 \mathrm{~nm}$ are governed by the d-d transitions in multilayered $\beta-\mathrm{Ni}(\mathrm{OH})_{2}$ [44], while the band at $398 \mathrm{~nm}$ is associated with the ${ }^{3} \mathrm{~A}_{2} \rightarrow{ }^{3} \mathrm{~T}_{1}(3 \mathrm{P})$ transition of $\mathrm{Ni}^{2+}$ in octahedral symmetry [45].
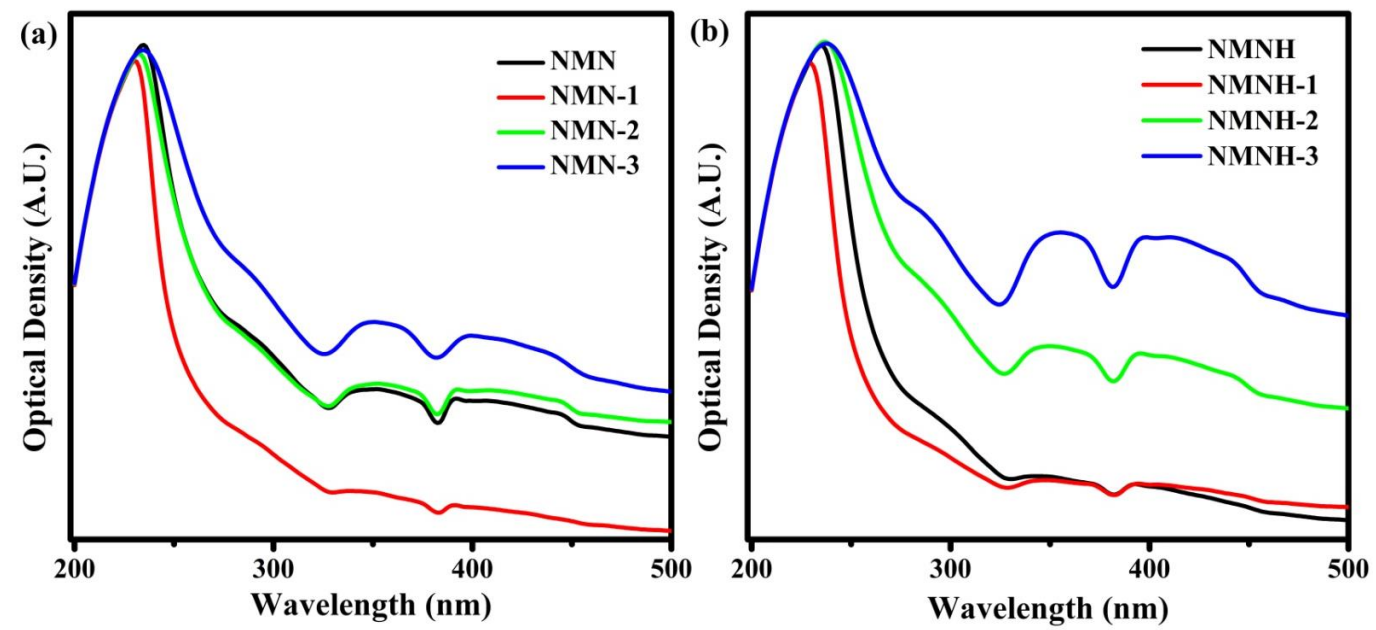

Figure 4. UV-vis spectroscopic studies of (a) NMN, NMN-1, NMN-2, and NMN-3; and (b) NMNH, NMNH-1, NMNH-2, and NMNH-3. 


\subsection{Electrochemical Studies}

\subsubsection{Electrode Preparation}

The working electrode was the synthesized nanocomposites made of $80 \%$ of active material, i.e., $\mathrm{NiMgOH}$ and $\mathrm{NiMgOH}-\mathrm{rGO}$, where $\mathrm{rGO}$ was taken as $0.5 \%, 1 \%$, and $1.5 \%$ by weight. The $10 \%$ of polyvinylidene fluoride (PVDF) acted as an organic binder, and $10 \%$ of activated carbon material was added, making the surface area chemically active. The three materials were mixed and made into a thick slurry by coating with a few drops of N-methyl pyrrolydine (NMP) coated on $1 \times 1 \mathrm{~cm}^{2} \mathrm{Ni}$ foam substrate uniformly, and heat treatment was given at $80^{\circ} \mathrm{C}$ for $12 \mathrm{~h}$. The electrochemical analysis was performed by three-electrode systems using $\mathrm{CH}$ instrument (CH Instruments, Inc., Austin, TX, USA).

\subsubsection{Cyclic Voltammetry Studies}

Using $6 \mathrm{M}$ of aq. $\mathrm{KOH}$ as the supporting electrolyte, the electrochemical performance of prepared nanocomposites was investigated in a three-electrode configuration. Figure $5 \mathrm{a}, \mathrm{b}$ show cyclic voltammetric features curves of $\mathrm{NiMgOH}$ and $\mathrm{NiMgOH}-\mathrm{rGO}$ nanocomposites @0.5\%,1\%, and 1.5\% by weight with $\mathrm{NaOH}$ and $\mathrm{NH} 4 \mathrm{OH}$ as reducing agents with the potential ranging from $-0.2 \mathrm{~V}$ to $0.6 \mathrm{~V}$ with $2-100 \mathrm{mV} / \mathrm{s} \mathrm{scan}$ rates, respectively. The area under the voltammogram increased with the scan rates, indicating high power characteristics [46]. The oxidation peak $(0.32 \mathrm{~V})$ and reduction peak $(0.19 \mathrm{~V})$ shifted toward positive and negative positions, respectively [47]. As increasing the potential scan rate led to an increase in current, this peak shift with increasing potential scan rate in $\mathrm{CV}$ plots can be attributed to the electrode's slow intrinsic electrochemical kinetics or/and ohmic limitation [48]. The redox peak in CV represents pseudocapacitive behavior of the composite and is attributed to the variation in oxidation states of $\mathrm{Ni}$ and $\mathrm{Mg}$.
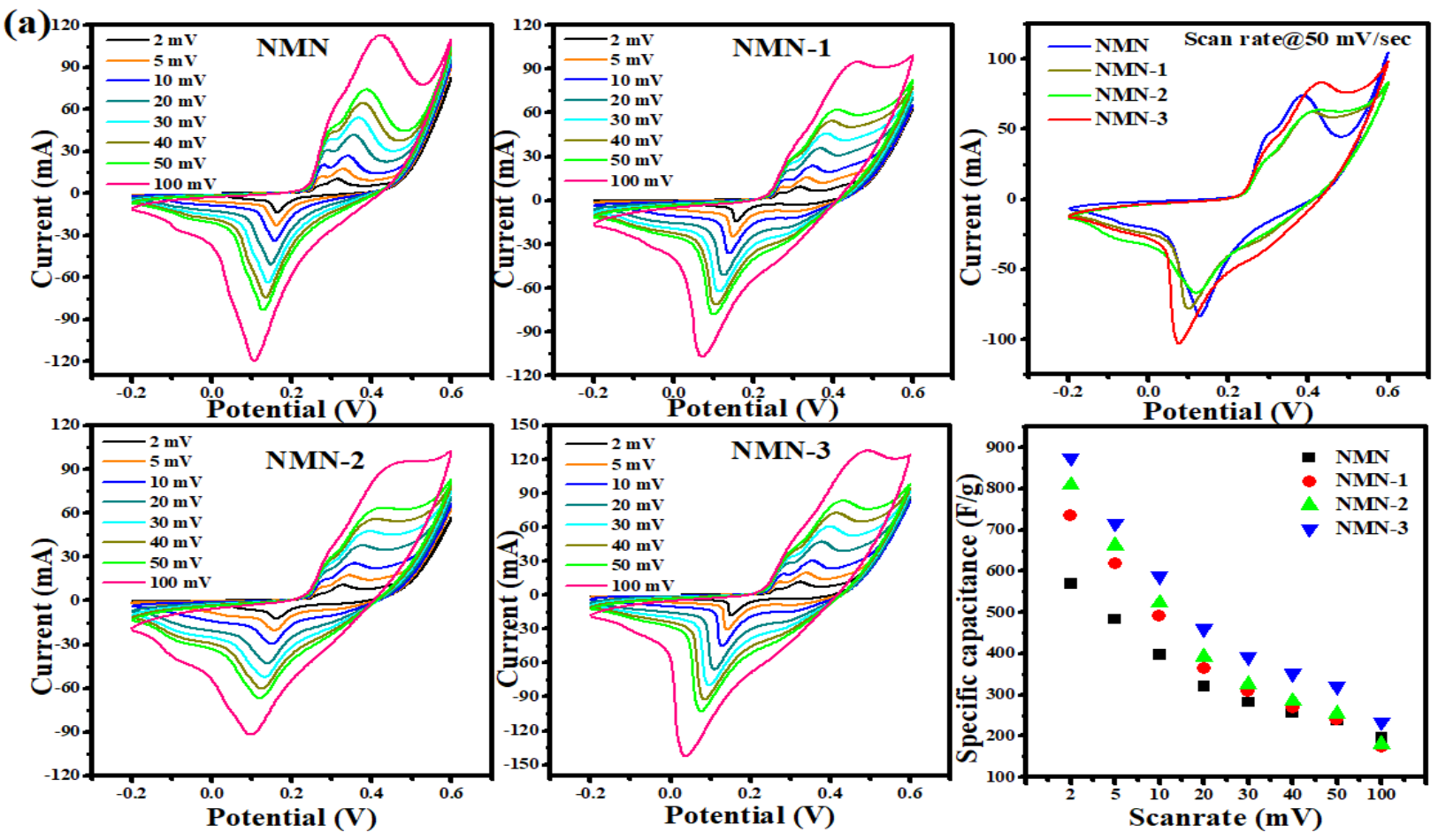

Figure 5. Cont. 

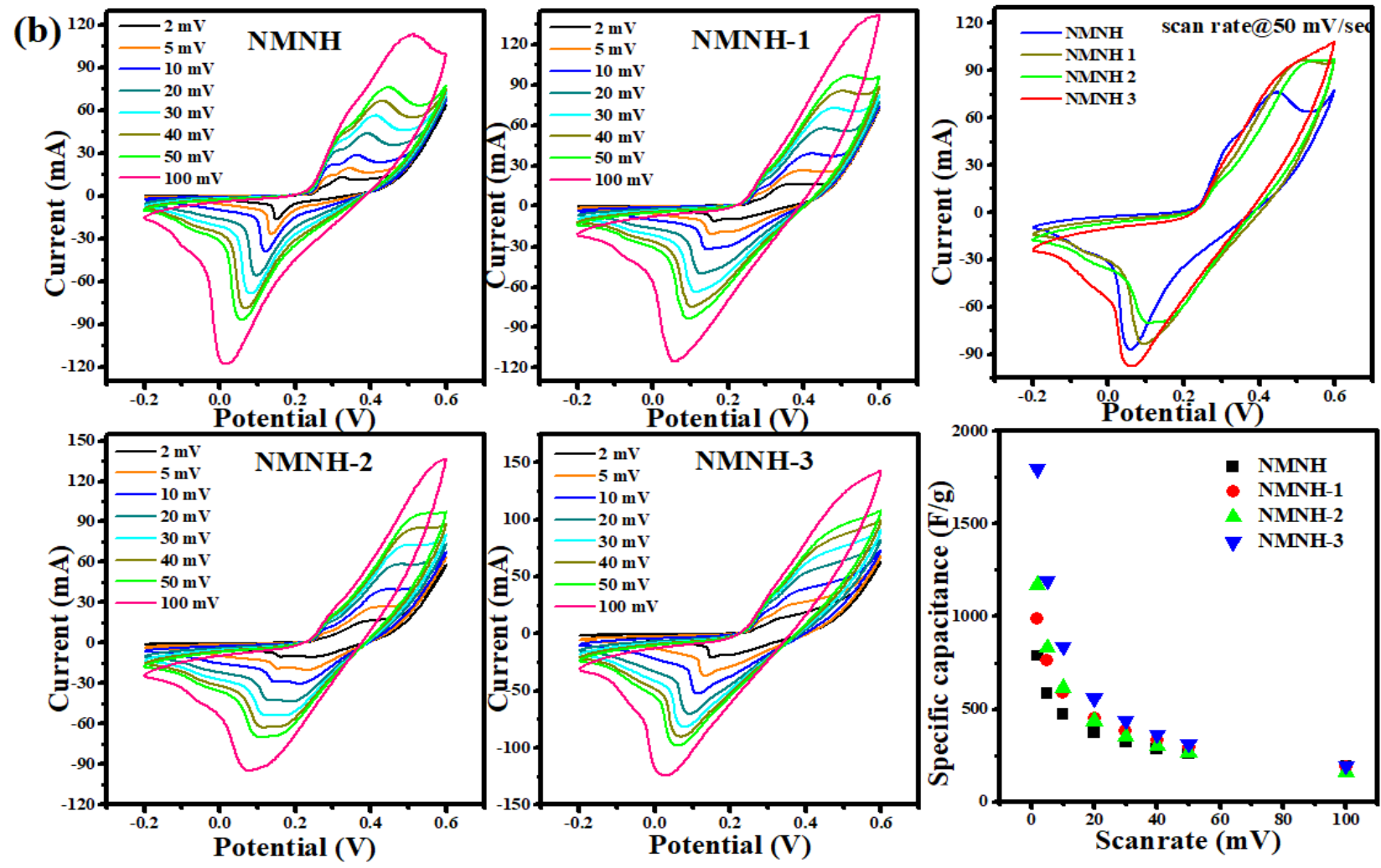

Figure 5. (a) Cyclic voltammetry studies of NMN, NMN-1, NMN-2, and NMN-3, and specific capacitance as a function of scan rate. (b) Cyclic voltammetry studies of NMNH, NMNH-1, NMNH-2, and NMNH-3, and specific capacitance as a function of scan rate.

The peak current density and integral area enclosed of NMN-3 were higher than those of other samples, which relate to the best capacitance. In Figure $5 \mathrm{~b}$ voltammograms, oxidation and reduction peaks observed at a $2 \mathrm{mV} / \mathrm{s}$ scan rate were 0.38 and 0.19 , respectively. Calculations were made on the specific capacitance and energy density of the synthesized samples by [49].

$$
\text { Specific Capacitance }(\mathrm{Csc})=\frac{\int I d v}{m \times v \times(v 2-v 1)}
$$

The specific capacitance increased with the concentration of rGO for all composites. This can be attributed to a change in the phase structure [50]. The composites synthesized by using $\mathrm{NaOH}$ showed a less specific capacitance than that of $\mathrm{NH}_{4} \mathrm{OH}$, and it may be due to the presence of $\mathrm{NaNO}_{3}$ in the final product. The NMNH-3 electrode showed a higher specific capacitance of $1793 \mathrm{~F} / \mathrm{g}$ at a scan rate of $2 \mathrm{mV} / \mathrm{s}$. The specific capacitance decreased with the scan rate accredited to inner active sites that cannot sustain the redox transitions [51].

\subsubsection{Galvanostatic Charge-Discharge Studies}

The galvanic charge-discharge measurements at the potential time frame with constant current value gave the charge storage nature of the electrode. These experiments used a current density of $1 \mathrm{~A} / \mathrm{g}$. All of the curves exhibited excellent electrochemical reversibility with no discernible deviations between cycles (Figure 6). The discharging time for all the samples was 350-790 s, which reveals an excellent capacitive characteristic of the material. The above GCD curves showed nonlinear behavior because it showed a pseudocapacitive behavior associated with non-faradaic EDLC's [52]. This confirms the faradaic characteristics of charge storage. 


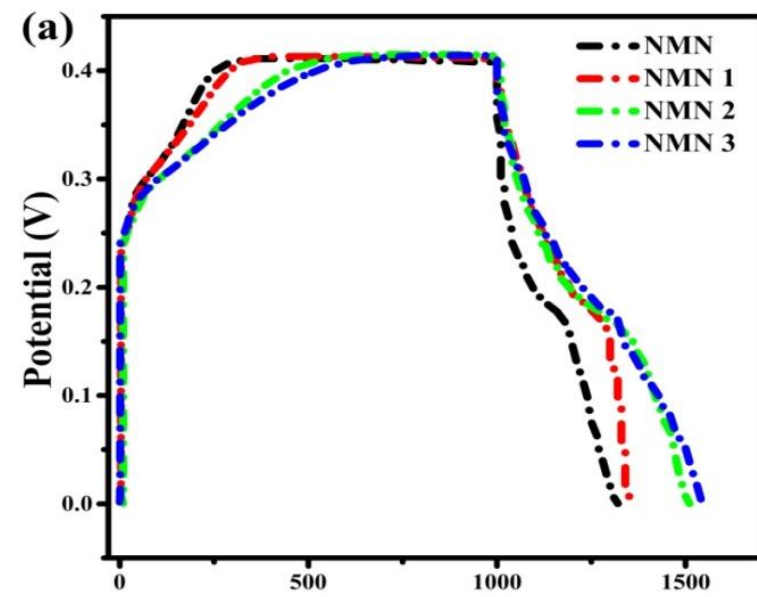

Time (s)

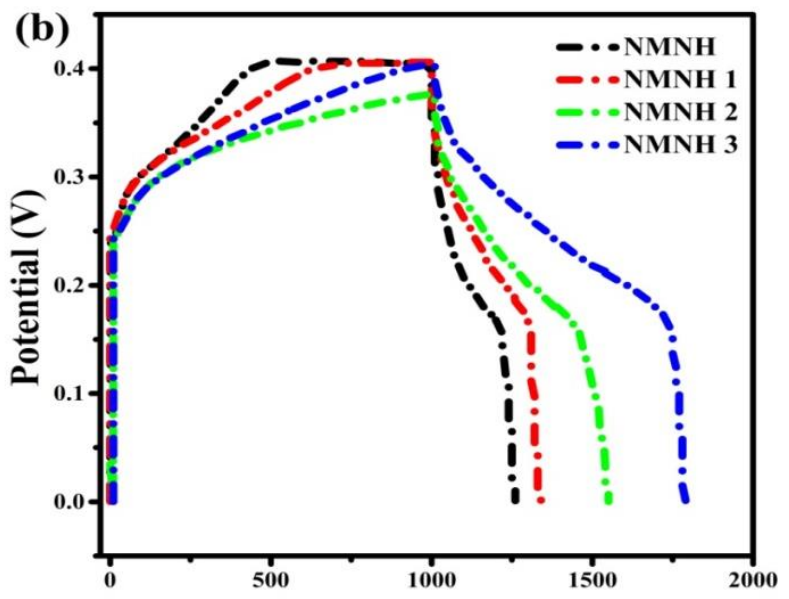

Time (s)

Figure 6. GCD curves of (a) NMN, NMN-1, NMN-2, and NMN-3; and (b) NMNH, NMNH-1, NMNH-2, and NMNH-3.

Specific capacitance was derived from the galvanostatic charge-discharge experiment and was calculated from the following equation [53].

$$
C=\frac{I \times \Delta t}{m \times \Delta V}
$$

where $C$ denotes the specific capacitance $(\mathrm{F} / \mathrm{g}) ; m$ denotes the active mass of the material on the working electrode (mg); $V$ denotes the potential window $(v)$; and $I, \Delta t$ denotes the discharge current (A) time(s). At a current density of $1 \mathrm{~A} / \mathrm{g}$, the specific capacitance was determined. The observed low capacity values were due to the iR drop within the capacitors. As illustrated in Figure 6a,b, the iR drop is a measure of equivalent series resistance that has an effect on the overall performance of a capacitor cell. Specific capacitance values calculated from GCD curves are listed in Table 3.

Table 3. Specific capacitance values from GCD and CV curves for NiMgOH-rGO samples.

\begin{tabular}{cccc}
\hline S.No & Name of Sample & $\begin{array}{c}\text { Specific Capacitance (F/g) } \\
\text { @ 2 } \mathbf{~ m ~ V / s}\end{array}$ & $\begin{array}{c}\text { Specific Capacitance from } \\
\text { GCD Curves @ 1 A/g }\end{array}$ \\
\hline 1 & NMN & 568 & 780 \\
2 & NMN-1 & 733 & 853 \\
3 & NMN-2 & 809 & 1243 \\
4 & NMN-3 & 874 & 1317 \\
5 & NMNH & 787 & 650 \\
6 & NMNH-1 & 984 & 850 \\
7 & NMNH-2 & 1170 & 1483 \\
8 & NMNH-3 & 1793 & 1977 \\
\hline
\end{tabular}

All the calculations from cyclic voltammetry (CV) and galvanostatic charge-discharge (CD) have their typical point of dependence factors as if they depend on materials, type of capacitors, and electrochemical systems. The difference in specific capacitance values is due to the different time scales of these two techniques [54]. In CV, the time of the experiment is well defined via the scan rate and potential window here. We considered the average current for calculating specific capacitance in the cyclic voltammogram method, while in galvanostatic studies, we fixed the charge-discharge current, thus finding a difference in specific capacitance measurement [55]. The values strongly depend upon scan rate (for CV) and current density (for GCD). Here, we report the highest capacitance values at lower scan rates $(2 \mathrm{mV} / \mathrm{s}$ for $\mathrm{CV})$ and lower current densities $(1 \mathrm{~A} / \mathrm{g}$ for GCD) as the supercapacitor is related to fast and quick charge storage. 
The EIS data were analyzed using Nyquist plots, as shown in Figure 7a,b. The Nyquist plot of Figure 7a indicates the capacitive behavior of NMN, while this behavior was further enhanced with the addition of $\mathrm{rGO}(0.5 \%, 1 \%$, and $1.5 \%)$ in the high-frequency region. The high-frequency deviations were caused by the diffusive resistance of ions in the electrolyte solution. The straight line in the low-frequency region represents the Warburg resistance $(\mathrm{Zw})$, which was caused by ion diffusion from the electrolyte solution to the working electrode. Semicircles, on the other hand, formed in the high-frequency region as a result of the low interfacial charge transfer phenomena [56].
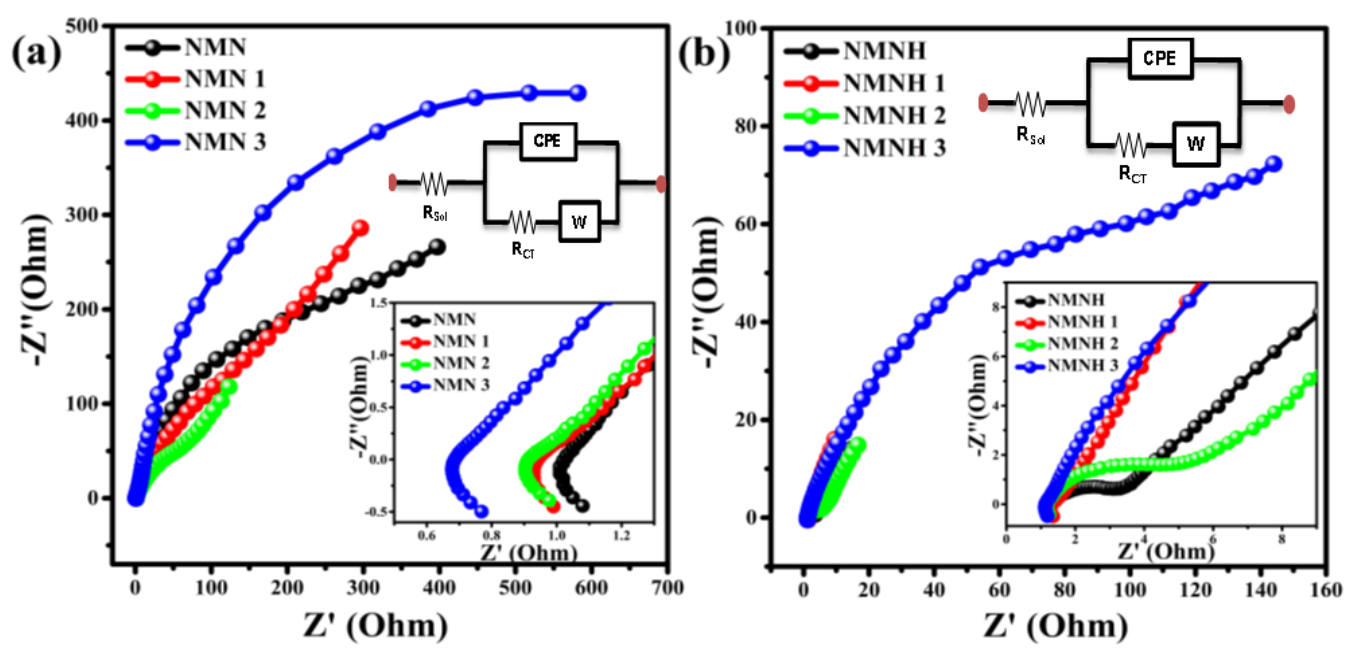

Figure 7. Nyquist plots of (a) NMN, NMN-1, NMN-2, NMN-3; and (b) NMNH, NMNH-1, NMNH2, NMNH-3 with corresponding equivalent circuits.

From Nyquist plots, we observed an interesting fact that most of the samples exhibited a dual contribution of charge transfer reactions. One is surface-controlled, as indicated by the depressed-circle portion, due to the electrode's direct contact with the electrolyte. The other type is diffusion-controlled, and it originates from internal regions such as grain boundaries, voids, and cracks, which are represented by a linear portion [57].

Quantitatively estimating all the system parameters, it is customary to fit the Nyquist plots using suitable equivalent circuits, and here, a modified Randel's circuit was employed. This circuit was composed of a charge transfer resistance (Rct) across the electrode/electrolyte interface and a constant-phase element (CPE). The fact that the $z^{\prime}$ axis had a non-zero intercept demonstrates the solution's resistance $\left(R_{S}\right)$. The impedance of the $\mathrm{CPE}$ is given by

$$
z_{C P E}=\frac{1}{Y(j \omega)^{n}}
$$

where $Y$ is a proportionality constant and the angular frequency ' $\omega$ ' equals $2 \pi \mathrm{f}$, with $(n)$ being the CPE exponent $(0 \leq n \leq 1)$ [58]. However, defects in real electrochemical cells, such as surface roughness, capacitor leak, and nonuniform current distribution, cause electrodes to function less than optimally. As a result, instead of the capacitive element (C), $Q$ or the constant-phase element (CPE) is commonly employed to describe nonideal behavior in electrodes. When the diffusion limit between the electrode and the nonreactive surface is limited, a separate Warburg impedance circuit element (W) must be introduced into Randel's equivalent circuit (current collector) [59]. The system parameters for NMN, NMN-1, NMN-2, and NMN-3; and NMNH, NMNH-1, NMNH-2, and NMNH-3 samples are reported in Table 4. 
Table 4. System parameters were obtained from the fitting of the Nyquist plots using the equivalent circuit shown in Figure 7 (inset).

\begin{tabular}{|c|c|c|c|c|c|}
\hline \multirow{2}{*}{ Electrode } & \multirow{2}{*}{ RS $(\Omega)$} & \multirow{2}{*}{$\operatorname{Rct}(\Omega)$} & \multicolumn{2}{|c|}{ CPE1 } & \multirow{2}{*}{$\frac{W}{\left(\Omega^{-1} \cdot s^{1 / 2}\right)}$} \\
\hline & & & Exponent $n$ & $Y_{0}\left(m \Omega^{-1} \cdot s^{n}\right)$ & \\
\hline NMN & 1.0 & 600 & 0.90 & 0.1 & 0.100 \\
\hline NMN-1 & 1.1 & 400 & 0.95 & 0.5 & 0.010 \\
\hline NMN-2 & 0.91 & 58 & 0.85 & 2.1 & 0.008 \\
\hline NMN-3 & 3.36 & 50 & 0.50 & 1.1 & 0.001 \\
\hline NMNH & 1.15 & 7.42 & 0.50 & 471.4 & 0.197 \\
\hline NMNH-1 & 1.13 & 5.6 & 0.60 & 1.0 & 0.05 \\
\hline NMNH-2 & 1.27 & 2.4 & 0.70 & 80.0 & 0.001 \\
\hline NMNH-3 & 1.32 & 2.0 & 0.95 & 1.0 & 0.1 \\
\hline
\end{tabular}

\section{Conclusions}

$\mathrm{NiMgOH}$ and $\mathrm{NiMgOH}-\mathrm{rGO}$ nanocomposites with different rGO loadings were synthesized using the co-precipitation method by using $\mathrm{NaOH}$ and $\mathrm{NH}_{4} \mathrm{OH}$ as reducing agents separately. XRD, FT-IR, and UV-visible spectroscopic studies confirmed the strong interaction between the elements of $\mathrm{NiMgOH}$ and $\mathrm{NiMgOH}-\mathrm{rGO}$. The average particle size was calculated using PSA, which confirms the uniform distribution in the range of 1-100 $\mathrm{nm}$ in diameter and single crystals in most synthesized nanocomposites. The specific capacitance calculated from GCD curves was $1977 \mathrm{~F} / \mathrm{g}$ at a $1 \mathrm{~A} / \mathrm{g}$ current density for $\mathrm{NiMgOH}-1.5 \% \mathrm{rGO}$ with $\mathrm{NH}_{4} \mathrm{OH}$ as a reducing agent. As the concentration of $\mathrm{rGO}$ increased from 0.5 to $1.5 \%$, the specific capacitance values increased compared to the samples without rGO. This confirms that the composition of rGO with $\mathrm{NiMgOH}$ enhanced the conductivity of composites.

Author Contributions: Conceptualization: C.S.C. and K.S.; methodology: C.S.C. and K.S.; software: M.M.K.; validation: K.S., V.D. and K.R.R.; formal analysis: K.S. and T.R.K.; investigation: K.S. and T.R.; resources: C.S.C.; data curation: K.S.; writing-original draft preparation: K.S. and T.R.; writing-review and editing: C.S.C., M.M.K., K.R.R., V.D.; visualization: C.S.C. and K.S.; supervision: C.S.C., M.M.K., K.R.R.; project administration: C.S.C.; funding acquisition: C.S.C. All authors have read and agreed to the published version of the manuscript.

Funding: This research was funded by Department of Science and Technology, through the DST SYST division with grant number SP/YO/2019/1599(G) at New Delhi.

Institutional Review Board Statement: Not applicable.

Informed Consent Statement: Not applicable.

Data Availability Statement: Not applicable.

Acknowledgments: The authors Chidurala Shilpa Chakra and Konda Shireesha would like to acknowledge the Department of Science and Technology for its generous financial support for the project through the DST SYST division SP/YO/2019/1599(G) at New Delhi.

Conflicts of Interest: The authors declare no conflict of interest.

\section{References}

1. Reddy, C.V.; Reddy, I.N.; Reddy, K.R.; Jaesool, S.; Yoo, K. Template-free synthesis of tetragonal Co-doped $\mathrm{ZrO}_{2}$ nanoparticles for applications in electrochemical energy storage and water treatment. Electrochim. Acta 2019, 317, 416-426. [CrossRef]

2. Chodankar, N.R.; Shinde, P.A.; Patil, S.J.; Hwang, S.K.; Raju, G.S.R.; Ranjith, K.S.; Dubal, D.P.; Huh, Y.S.; Han, Y.K. Solution-free self-assembled growth of ordered tricopper phosphide for efficient and stable hybrid supercapacitor. Energy Storage Mater. 2021, 39, 194-202. [CrossRef]

3. Lokhande, P.E.; Pawar, K.; Chavan, U.S. Chemically deposited ultrathin $\alpha-\mathrm{Ni}(\mathrm{OH})_{2}$ nanosheet using surfactant on Ni foam for high performance supercapacitor application. Mater. Sci. Energy Technol. 2018, 1, 166-170. [CrossRef]

4. Edition, E. New supercapacitor for faster electric vehicles. Auto Technol. 2020, 15, 1-4.

5. Liang, J.; Zhao, Y.; Guo, L.; Li, L. Flexible free-standing graphene/ $\mathrm{SnO}_{2}$ nanocomposites paper for Li-ion battery. ACS Appl. Mater. Interfaces 2012, 4, 5742-5748. [CrossRef] 
6. Zheng, J.; Cheng, K.; Zhang, R.; Yang, Y.; Wu, Y.; Yu, P. Si Quantum dots assist synthesized microflower-like Si/MoS 2 composites for supercapacitors. Crystals 2020, 10, 846. [CrossRef]

7. Phul, R.; Khan, M.A.M.; Sardar, M.; Ahmed, J.; Ahmad, T. Multifunctional electrochemical properties of synthesized non-precious iron oxide nanostructures. Crystals 2020, 10, 751. [CrossRef]

8. Chodankar, N.R.; Bagal, I.V.; Ryu, S.W.; Kim, D.H. Hybrid material passivation approach to stabilize the silicon nanowires in aqueous electrolyte for high-energy efficient supercapacitor. Chem. Eng. J. 2019, 362, 609-618. [CrossRef]

9. Lokhande, P.E.; Chavan, U.S. Nanostructured $\mathrm{Ni}(\mathrm{OH})_{2} / \mathrm{rGO}$ composite chemically deposited on Ni foam for high performance of supercapacitor applications. Mater. Sci. Energy Technol. 2019, 2, 52-56. [CrossRef]

10. Li, Q.; Hu, Z.; Liu, Z.; Zhao, Y.; Li, M.; Meng, J.; Tian, X.; Xu, X.; Mai, L. Recent advances in nanowire-based, flexible, freestanding electrodes for energy storage. Chem.-A Eur. J. 2018, 24, 18307-18321. [CrossRef]

11. Qi, Y.; Liu, Y.; Zhu, R.; Wang, Q.; Luo, Y.; Zhu, C.; Lyu, Y. Rapid synthesis of $\mathrm{Ni}(\mathrm{OH})_{2} /$ graphene nanosheets and $\mathrm{NiO} @ \mathrm{Ni}(\mathrm{OH})_{2}$ /graphene nanosheets for supercapacitor applications. New J. Chem. 2019, 43, 3091-3098. [CrossRef]

12. Chou, S.; Wang, J.; Chew, S.; Liu, H.; Dou, S. Electrochemistry communications electrodeposition of $\mathrm{MnO}_{2}$ nanowires on carbon nanotube paper as free-standing, flexible electrode for supercapacitors. Electrochem. Commun. 2008, 10, 1724-1727. [CrossRef]

13. Wang, Y.; Yin, Z.; Li, X.; Guo, H.; Zhang, D.; Wang, Z. Smartly tailored $\mathrm{Co}(\mathrm{OH})_{2}-\mathrm{Ni}(\mathrm{OH})_{2}$ heterostructure on nickel foam as binder-free electrode for high-energy hybrid capacitors. Electrochim. Acta 2019, 309, 140-147. [CrossRef]

14. Ji, S.H.; Chodankar, N.R.; Jang, W.S.; Kim, D.H. High mass loading of $\mathrm{h}-\mathrm{WO}_{3}$ and $\alpha-\mathrm{MnO}_{2}$ on flexible carbon cloth for high-energy aqueous asymmetric supercapacitor. Electrochim. Acta 2019, 299, 245-252. [CrossRef]

15. Jablonskiene, J.; Simkunaite, D.; Vaiciuniene, J.; Stalnionis, G.; Drabavicius, A.; Jasulaitiene, V.; Pakstas, V.; TamasauskaiteTamasiunaite, L.; Norkus, E. Synthesis of carbon-supported mno2 nanocomposites for supercapacitors application. Crystals 2021, 11, 784. [CrossRef]

16. Liang, T.; Xuan, H.; Xu, Y.; Gao, J.; Han, X.; Yang, J.; Han, P.; Wang, D.; Du, Y. Rational Assembly of CoAl-Layered Double Hydroxide on Reduced Graphene Oxide with Enhanced Electrochemical Performance for Energy Storage. ChemElectroChem 2018, 5, 2424-2434. [CrossRef]

17. Yin, J.; Zhou, G.; Gao, X.; Chen, J.; Zhang, L.; Xu, J. $\alpha$-and $\beta$-Phase Ni-Mg Hydroxide for High Performance Hybrid Supercapacitors. Nanomaterials 2019, 9, 1686. [CrossRef]

18. Memon, J.; Sun, J.; Meng, D.; Ouyang, W.; Memon, M.A.; Huang, Y.; Yan, S.; Geng, J. Synthesis of graphene/Ni-Al layered double hydroxide nanowires and their application as an electrode material for supercapacitors. J. Mater. Chem. A 2014, 2, 5060-5067. [CrossRef]

19. Vidotti, M.; Salvador, R.P.; Ponzio, E.A.; de Torresi, S.I.C. Mixed Ni/Co hydroxide nanoparticles synthesized by sonochemical method. J. Nanosci. Nanotechnol. 2007, 7, 3221-3226. [CrossRef]

20. Li, X.; Khalafallah, D.; Wu, Z.; Zhi, M.; Hong, Z. Silver incorporated partially reduced NiCo-layered double hydroxide frameworks for asymmetric supercapacitors. J. Energy Storage 2020, 31, 101578. [CrossRef]

21. Yu, S.; Zhang, Y.; Lou, G.; Wu, Y.; Zhu, X.; Chen, H.; Shen, Z.; Fu, S.; Bao, B.; Wu, L. Synthesis of NiMn-LDH nanosheet@Ni $\mathrm{S}_{2}$ nanorod hybrid structures for supercapacitor electrode materials with ultrahigh specific capacitance. Sci. Rep. 2018, 8, 5246. [CrossRef]

22. Zhang, W.; Zhang, P.; Wang, Y.; Li, J. Preparation of $\mathrm{Mg}(\mathrm{OH})_{2}$ nanosheets and self-assembly of its flower-like nanostructure via precipitation method for heat-resistance application. Integr. Ferroelectr. 2015, 163, 148-154. [CrossRef]

23. Stephen, A. Protective Coatings for Magnesium Alloys; IntechOpen: Rijeka, Croatia, 2011.

24. Song, G.; StJohn, D. Corrosion behaviour of magnesium in ethylene glycol. Corros. Sci. 2004, 46, 1381-1399. [CrossRef]

25. Kang, J.; Schwendeman, S.P. Comparison of the effects of $\mathrm{Mg}(\mathrm{OH})_{2}$ and sucrose on the stability of bovine serum albumin encapsulated in injectable poly(D,L-lactide-co-glycolide) implants. Biomaterials 2002, 23, 239-245. [CrossRef]

26. Zaman, N.; Malik, R.A.; Alrobei, H.; Kim, J.; Latif, M.; Hussain, A.; Maqbool, A.; Karim, R.A.; Saleem, M.; Rafiq, M.A.; et al. Structural and electrochemical analysis of decarburized graphene electrodes for supercapacitor applications. Crystals 2020, 10, 1043. [CrossRef]

27. Kumar, R.; Youssry, S.M.; Abdel-Galeil, M.M.; Matsuda, A. One-pot synthesis of reduced graphene oxide nanosheets anchored $\mathrm{ZnO}$ nanoparticles via microwave approach for electrochemical performance as supercapacitor electrode. J. Mater. Sci. Mater. Electron. 2020, 31, 15456. [CrossRef]

28. Goswami, M.; Saraf, M.; Singh, B.; Mobin, S.M. Physicochemical and electrochemical behaviours of manganese oxide electrodes for supercapacitor application. J. Energy Storage 2020, 28, 101228.

29. Li, Y.; Song, Q.; Fan, B.; Zhang, R. Effects of reducing agents on the synthesis of Ag/rGO nanocomposites. Mater. Res. Express 2017, 4, 015014. [CrossRef]

30. Saleem, H.; Haneef, M.; Abbasi, H.Y. Synthesis route of reduced graphene oxide via thermal reduction of chemically exfoliated graphene oxide. Mater. Chem. Phys. 2018, 204, 1-7. [CrossRef]

31. De Cremoux, B.; Hirtz, P.; Ricciardi, J. Comment on "miscibility gaps in quaternary III/V alloys". J. Cryst. Growth 1983, 61, 177-178. [CrossRef]

32. Kovalev, A.I.; Wainstein, D.L.; Rashkovskiy, A.Y.; Gago, R.; Soldera, F.; Endrino, J.L.; Fox-Rabinovich, G.S. Interface-induced plasmon nonhomogeneity in nanostructured metal-dielectric planar metamaterial. J. Nanomater. 2015, 2015, 1-9. [CrossRef]

33. Zboril, R.; Mashlan, M.; Petridis, D. Iron (III) Oxides from Thermal Processes s Synthesis. Chem. Mater. 2002, 14, 969-982. [CrossRef] 
34. Kulasekarapandian, K.; Jayanthi, S.; Muthukumari, A.; Arulsankar, A.; Sundaresan, B. Preparation and Characterization of PVC-PEO Based Polymer Blend Electrolytes Complexed With Lithium Perchlorate. Int. J. Eng. Res. Dev. 2013, 5, 30-39.

35. Li, Y.; Yi, R.; Yan, A.; Deng, L.; Zhou, K.; Liu, X. Facile synthesis and properties of $\mathrm{ZnFe}_{2} \mathrm{O}_{4}$ and $\mathrm{ZnFe}_{2} \mathrm{O}_{4} /$ polypyrrole core-shell nanoparticles. Solid State Sci. 2009, 11, 1319-1324. [CrossRef]

36. Mazen, S.A.; Ahmed, M.A.; Sabrah, B.A. Thermal studies on the electrical conduction mechanism of $\mathrm{CuFe}_{2} \mathrm{O}_{4}$. Thermochim. Acta 1982, 56, 229-233. [CrossRef]

37. Babar, P.T.; Pawar, B.S.; Ahmed, A.T.A.; Sekar, S.; Lee, S.; Sankapal, B.R.; Im, H.; Kim, J.H.; Pawar, S.M. Synthesis of nickel hydroxide/reduced graphene oxide composite thin films for water splitting application. Int. J. Energy Res. 2020, 44, 10908-10916. [CrossRef]

38. <monospace>Huang, E.-W.; Hung, G.-Y.; Lee, S.Y.; Jain, J.; Chang, K.-P.; Chou, J.J.; Yang, W.-C.; Liaw, P.K. Mechanical and Magnetic Properties of the High-Entropy Alloys for Combinatorial Approaches. Crystals 2020, 10, 200.

39. Cui, H.; Xue, J.; Ren, W.; Wang, M. Ultra-high specific capacitance of $\beta-\mathrm{Ni}(\mathrm{OH}) 2$ monolayer nanosheets synthesized by an exfoliation-free sol-gel route. J. Nanoparticle Res. 2014, 16, 1-9. [CrossRef]

40. Elshahawy, A.M.; Ho, K.H.; Hu, Y.; Fan, Z.; Hsu, Y.W.B.; Guan, C.; Ke, Q.; Wang, J. Microwave-assisted hydrothermal synthesis of nanocrystal $\beta-\mathrm{Ni}(\mathrm{OH})_{2}$ for supercapacitor applications. CrystEngComm 2016, 18, 3256-3264. [CrossRef]

41. Ansari, A.; Ali, A.; Asif, M. Microwave-assisted MgO NP catalyzed one-pot multicomponent synthesis of polysubstituted steroidal pyridines. New J. Chem. 2018, 42, 184-197. [CrossRef]

42. Tan, L.L.; Ong, W.J.; Chai, S.P.; Mohamed, A.R. Reduced graphene oxide- $\mathrm{TiO}_{2}$ nanocomposite as a promising visible-light-active photocatalyst for the conversion of carbon dioxide. Nanoscale Res. Lett. 2013, 8, 1-9. [CrossRef]

43. Bhargava, R.; Khan, S. Effect of reduced graphene oxide (rGO) on structural, optical, and dielectric properties of $\mathrm{Mg}(\mathrm{OH})_{2} / \mathrm{rGO}$ nanocomposites. Adv. Powder Technol. 2017, 28, 2812-2819. [CrossRef]

44. Halder, M.; Islam, M.M.; Singh, P.; Singha Roy, A.; Islam, S.M.; Sen, K. Sustainable Generation of Ni(OH $)_{2} \mathrm{Nanoparticles} \mathrm{for}$ the Green Synthesis of 5-Substituted $1 \mathrm{H}$-Tetrazoles: A Competent Turn on Fluorescence Sensing of $\mathrm{H}_{2} \mathrm{O}_{2}$. ACS Omega 2018, 3 , 8169-8180. [CrossRef]

45. Harvey, A.; He, X.; Godwin, I.J.; Backes, C.; McAteer, D.; Berner, N.C.; McEvoy, N.; Ferguson, A.; Shmeliov, A.; Lyons, M.E.G.; et al. Production of $\mathrm{Ni}(\mathrm{OH})_{2}$ nanosheets by liquid phase exfoliation: From optical properties to electrochemical applications. J. Mater. Chem. A 2016, 4, 11046-11059. [CrossRef]

46. Xie, M.; Duan, S.; Shen, Y.; Fang, K.; Wang, Y.; Lin, M.; Guo, X. In-Situ-Grown Mg $(\mathrm{OH})_{2}$-Derived Hybrid $\alpha-\mathrm{Ni}(\mathrm{OH})_{2}$ for Highly Stable Supercapacitor. ACS Energy Lett. 2016, 1, 814-819. [CrossRef]

47. Zheng, J.H.; Zhang, R.M.; Wang, X.G.; Yu, P.F. Synthesizing a flower-like $\mathrm{NiO}$ and ZnO composite for supercapacitor applications. Res. Chem. Intermed. 2018, 44, 5569-5582. [CrossRef]

48. Cheng, R.; Hu, T.; Zhang, H.; Wang, C.; Hu, M.; Yang, J.; Cui, C.; Guang, T.; Li, C.; Shi, C.; et al. Understanding the lithium storage mechanism of $\mathrm{Ti}_{3} \mathrm{C}_{2} \mathrm{TxMXene.} \mathrm{J.} \mathrm{Phys.} \mathrm{Chem.} \mathrm{C} \mathrm{2019,} \mathrm{123,} \mathrm{1099-1109.} \mathrm{[CrossRef]}$

49. Kim, B.K.; Sy, S.; Yu, A.; Zhang, J. Electrochemical Supercapacitors for Energy Storage and Conversion. In Handbook of Clean Energy Systems; John Whiley and Sons: Hoboken, NJ, USA, 2015; pp. 1-25.

50. Su, W.; Lin, T.; Chu, W.; Zhu, Y.; Li, J.; Zhao, X. Novel synthesis of RGO/NiCoAl-LDH nanosheets on nickel foam for supercapacitors with high capacitance. RSC Adv. 2016, 6, 113123-113131. [CrossRef]

51. Patil, S.J.; Lokhande, V.C.; Chodankar, N.R.; Lokhande, C.D. Chemically prepared $\mathrm{La}_{2} \mathrm{Se}_{3}$ nanocubes thin film for supercapacitor application. J. Colloid Interface Sci. 2016, 469, 318-324. [CrossRef] [PubMed]

52. Mundy, A.; Plett, G.L. Reduced-order physics-based modeling and experimental parameter identification for non-Faradaic electrical double-layer capacitors. J. Energy Storage 2016, 7, 167-180. [CrossRef]

53. Zheng, D.; Zhao, F.; Li, Y.; Qin, C.; Zhu, J.; Hu, Q.; Wang, Z.; Inoue, A. Flexible NiO micro-rods/nanoporous Ni/metallic glass electrode with sandwich structure for high performance supercapacitors. Electrochim. Acta 2019, 297, 767-777. [CrossRef]

54. Palagonia, M.S.; Erinmwingbovo, C.; Brogioli, D.; La Mantia, F. Comparison between cyclic voltammetry and differential charge plots from galvanostatic cycling. J. Electroanal. Chem. 2019, 847, 113170. [CrossRef]

55. Lämmel, C.; Schneider, M.; Weiser, M.; Michaelis, A. Investigations of electrochemical double layer capacitor (EDLC) materials-A comparison of test methods. Materwiss. Werksttech. 2013, 44, 641-649. [CrossRef]

56. Liu, Y.; Wang, R.; Yan, X. Synergistic effect between ultra-small nickel hydroxide nanoparticles and reduced graphene oxide sheets for the application in high-performance asymmetric supercapacitor. Sci. Rep. 2015, 5, 11095. [CrossRef] [PubMed]

57. Xie, M.; Xu, Z.; Duan, S.; Tian, Z.; Zhang, Y.; Xiang, K.; Lin, M.; Guo, X.; Ding, W. Facile growth of homogeneous Ni(OH) 2 coating on carbon nanosheets for high-performance asymmetric supercapacitor applications. Nano Res. 2018, 11, 216-224. [CrossRef]

58. Divya, V.; Mondal, S.; Sangaranarayanan, M. V Shape-Controlled Synthesis of Palladium Nanostructures from Flowers to Thorns: Electrocatalytic Oxidation of Ethanol. J. Nanosci. Nanotechnol. 2018, 19, 758-769. [CrossRef] [PubMed]

59. Bhargava, A.; Alarco, J.A.; Mackinnon, I.D.R.; Page, D.; Ilyushechkin, A. Synthesis and characterisation of nanoscale magnesium oxide powders and their application in thick films of $\mathrm{Bi}_{2} \mathrm{Sr}_{2} \mathrm{CaCu}_{2} \mathrm{O}_{8}$. Mater. Lett. 1998, 34, 133-142. [CrossRef] 